\title{
Fabrication of a Miniature Zinc Aluminum Oxide Nanowire Array Gas Sensor and Application for Environmental Monitoring
}

\author{
Chin-Guo Kuo, ${ }^{1}$ Chi-Wu Huang, ${ }^{1}$ Jung-Hsuan Chen, ${ }^{2}$ and Yueh-Han Liu ${ }^{1}$ \\ ${ }^{1}$ Department of Industrial Education, National Taiwan Normal University, Taipei 10610, Taiwan \\ ${ }^{2}$ Material and Chemical Research Laboratories, Industrial Technology Research Institute, Hsinchu 31040, Taiwan \\ Correspondence should be addressed to Jung-Hsuan Chen; jhc2369@yahoo.com.tw
}

Received 10 April 2014; Accepted 14 May 2014; Published 10 June 2014

Academic Editor: Ho Chang

Copyright (C) 2014 Chin-Guo Kuo et al. This is an open access article distributed under the Creative Commons Attribution License, which permits unrestricted use, distribution, and reproduction in any medium, provided the original work is properly cited.

A miniature n-type semiconductor gas sensor was fabricated successfully using zinc aluminum oxide nanowire array and applied to sense oxygen. The present study provided a novel method to produce zinc aluminum alloy nanowire $80 \mathrm{~nm}$ in diameter by the vacuum die casting technique and then obtain zinc aluminum oxide nanowire array using the thermal oxidation technique. The gas sensing properties were evaluated through the change of the sensitivity. The factors influencing the sensitivity of the gas sensor, such as the alloy composition, operating temperature, and oxygen concentration, were investigated further. Experimental results indicated that the maximum sensitivity could be acquired when the weight percentage of aluminum was $5 \%$ in zinc aluminum alloy at the operating temperature of $200^{\circ} \mathrm{C}$.

\section{Introduction}

Oxygen gas monitors are widely used for employee and environmental safety. A rapid decrease of oxygen can make a very dangerous environment for employees and cause them to lose consciousness suddenly. Based on the fact mentioned, it is important to have an oxygen gas monitor for some special operating environments such as mines, pharmaceutical, semiconductor, and cryogenic supplier [14].

Metal oxide semiconductor sensors are most commonly utilized for the gas detection due to their low cost and flexibility in production $[5,6]$. The detection principle of the conductive sensor is based on the change of the resistance of a semiconductor thin film upon the adsorption of gas molecules on the surface. The sensitivity of the thin film is strongly related to surface reaction. Some important factors influencing the surface reactions of gas sensors, such as chemical components, microstructures of sensing layers, temperature, and humidity, are investigated [7-10]. Among those factors, the main approaches for increasing the gas sensitivity of the sensing materials are the size effects and doping by metal or other metal oxides [11-14].

Korotcenkov et al. [11] reported that the grain size effects in the sensor response of nanostructures $\mathrm{SnO}_{2}$ and $\mathrm{In}_{2} \mathrm{O}_{3}$ based thin film gas sensor and indicated the grain size can control almost all operating characteristics of solid state gas sensors such as sensor response, response times, recovery times, and stability and dependence on air humidity. However, the sensing mechanisms of the metal oxide gas sensors were too complicated to evaluate simply. The optimal grain size should be based on the detailed consideration of the parameters of sensors designed.

Chaudhari and his coworkers [14] reported the sensing characteristics of undoped and doped $\mathrm{TiO}_{2}$ gas sensor and tried to improve the sensing properties of $\mathrm{TiO}_{2}$ by addition of a small amount of various metal oxides, such as $\mathrm{Al}_{2} \mathrm{O}_{3}$. Their experimental results showed that $\mathrm{TiO}_{2}$ sensor loaded with 5 wt. $\% \mathrm{Al}_{2} \mathrm{O}_{3}$ and $0.5 \mathrm{wt} . \% \mathrm{Pd}$ would increase the sensitivity to $\mathrm{H}_{2} \mathrm{~S}$ gas.

Since the gas sensing mechanism is a surface reaction, use of nanostructure materials is expected to improve gas 


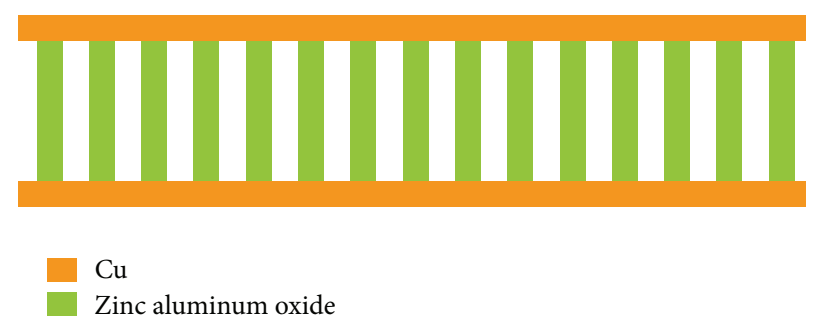

FIGURE 1: Schematic diagram of the prepared zinc aluminum oxide nanowire array gas sensor.



(a)

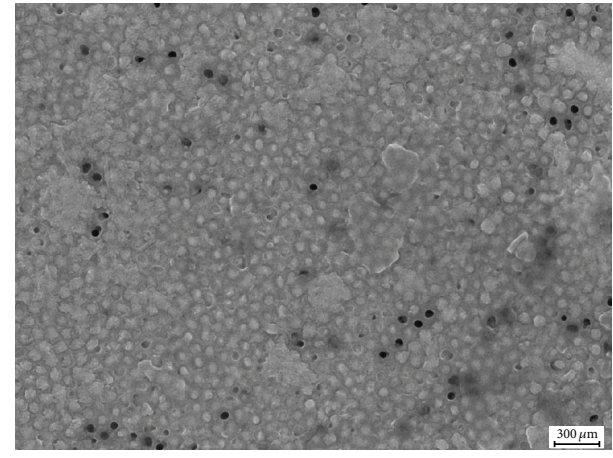

(b)

FIGURE 2: SEM images: (a) a porous alumina membrane with an ordering pore diameter of $80 \mathrm{~nm}$ and (b) zinc aluminum nanowire arrays fabricated in the alumina nanomold by the vacuum die casting process.

sensing characteristics. The present study combined both approaches mentioned above to fabricate a miniature metal oxide nanowire array sensor and apply it to the environmental monitor responding to oxygen. In addition, this study was also focused on changes of sensitivity of the gas sensor caused by factors such as chemical components, working temperature, and oxygen concentration.

\section{Experimental Procedure}

In this study, the metal oxide semiconductor gas sensor was carried out with a zinc aluminum oxide nanowire array incorporating a high surface area and aspect ratio.

Zinc aluminum oxide nanowires were fabricated using anodic aluminum oxide (AAO) as a template. The experimental procedure could be divided into four parts. First of all, an anodic alumina nanomold was obtained by etching a pure aluminum sheet with a purity of $99.7 \mathrm{wt} . \%$ in $0.3 \mathrm{M}$ oxalic acid solution. Two steps of anode treatments were applied to obtain more uniform nanopores in this experiment. The first step of the anode treatment was carried out at a voltage $40 \mathrm{~V}$ and a temperature of $25^{\circ} \mathrm{C}$ for one hour. Afterward, removing alumina thin film from the surface of aluminum sheet was performed in the mixture of $6 \%$ phosphoric acid solution and $2 \%$ chromic acid solution at a temperature of $60^{\circ} \mathrm{C}$. The second step of the anode treatment was carried out in the same process conditions indicated in the first step for 6 hours. Finally, aluminum substrate was removed using copper chloride solution and then the anodic alumina nanomold with a pore diameter of $80 \mathrm{~nm}$ could be obtained.
The second part of the procedure was the fabrication of zinc aluminum alloy by the vacuum melting method. The high purity of zinc and aluminum scraps were mixed and placed in a quartz glass tube. In order to prevent metal from oxidation during melting, the vacuum was extracted using a molecular turbo pump and kept at $3 \times 10^{-6}$ torr. Then, the glass tube was placed in a furnace and the temperature was increased to $750^{\circ} \mathrm{C}$ for several minutes until all metal smelted and mixed well. After cooling, zinc aluminum alloy was obtained. More detailed process of the vacuum melting was described in our previous study $[15,16]$. In this study, 3 zinc aluminum alloys with the different aluminum contents, $2 \%, 5 \%$, and $10 \%$, were prepared as listed in Table 1 .

Furthermore, zinc aluminum alloy nanowire array was produced using thehigh vacuum die casting technique. A piece of zinc aluminum alloy and an alumina template were placed inside the chamber in which the vacuum pressure was maintained at $10^{-6}$ torr. After the chamber was heated to $750^{\circ} \mathrm{C}$, a hydraulic force was applied to the molten zinc aluminum alloy. During casting, the molten alloy was injected into the anodic alumina nanomold forming alloy nanowire array. The force required to introduce molten alloy into the nanomold is proportional to the surface tension of the melt. The surface tension of the molten zinc at $750^{\circ} \mathrm{C}$ is $719.7 \mathrm{dyne} / \mathrm{cm}$ and the surface tension of the molten aluminum at $750^{\circ} \mathrm{C}$ is $857.05 \mathrm{dyne} / \mathrm{cm}$ [17].

Therefore, the surface tension of the molten zinc aluminum alloy at $750^{\circ} \mathrm{C}$ can be calculated based on the alloy components. Additionally, the pressure for the molten metal injection into nanomold can be evaluated as follows [18]: 


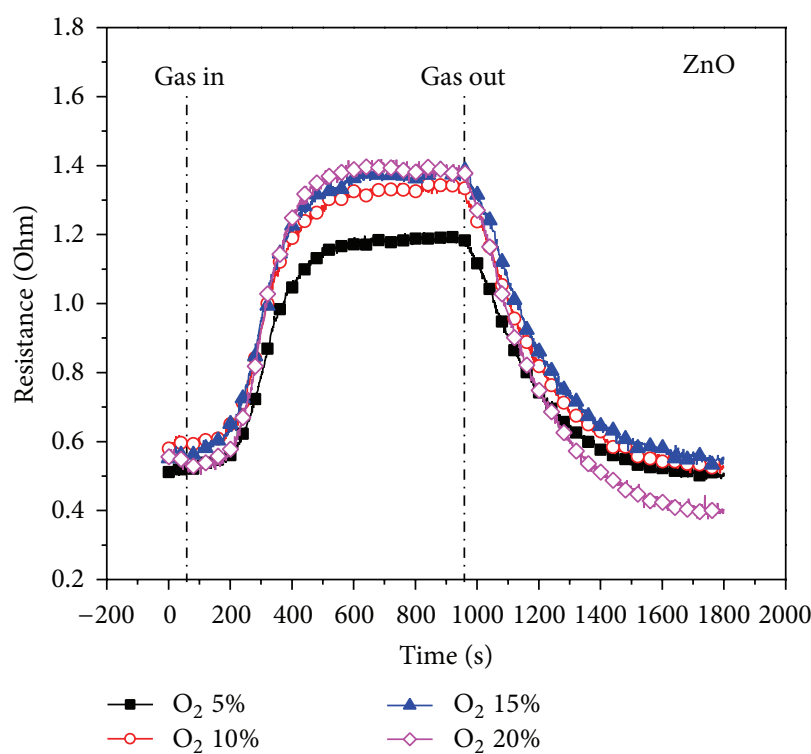

(a)

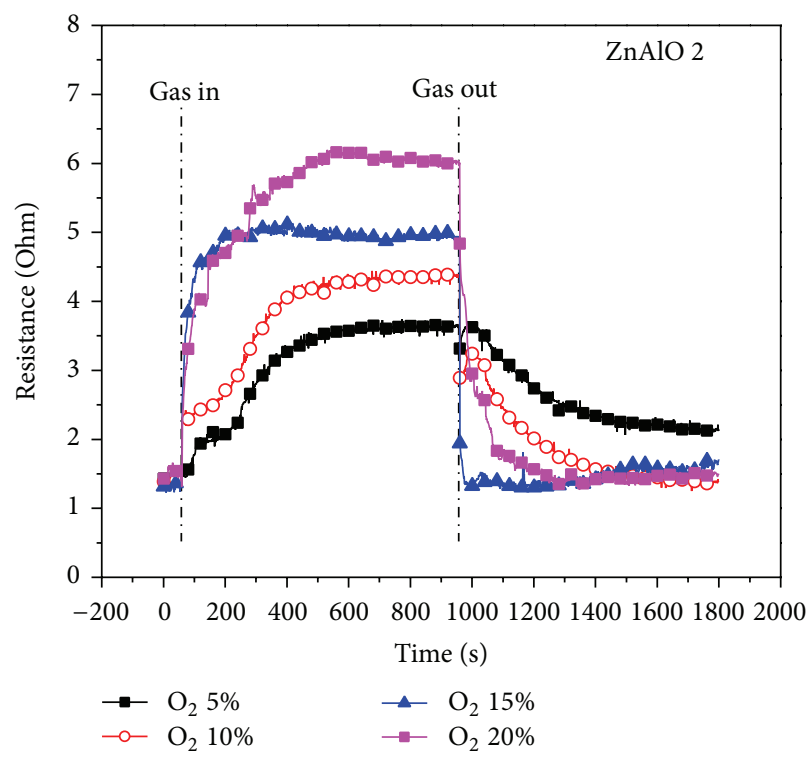

(c)

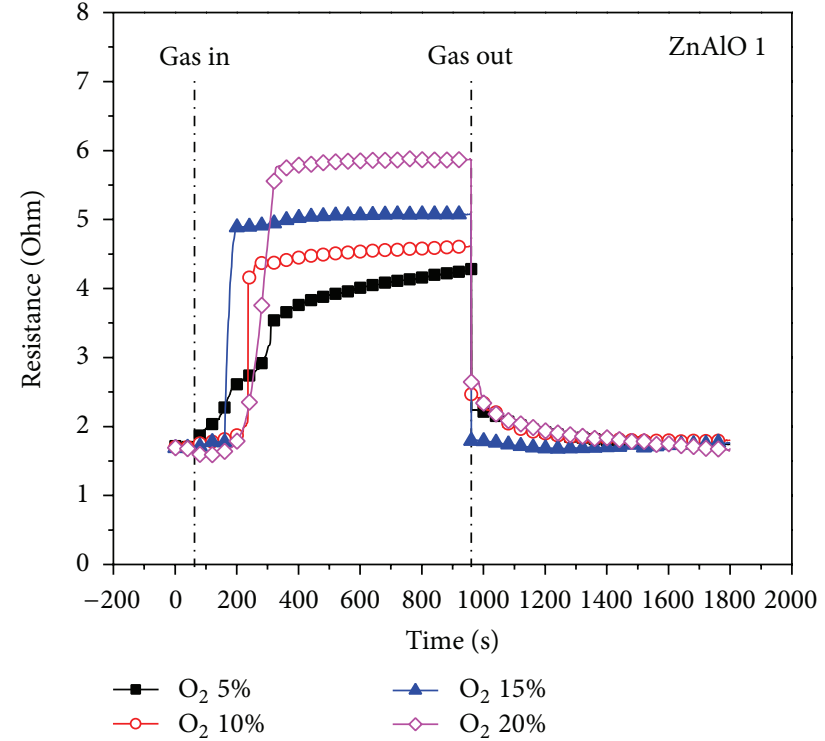

(b)

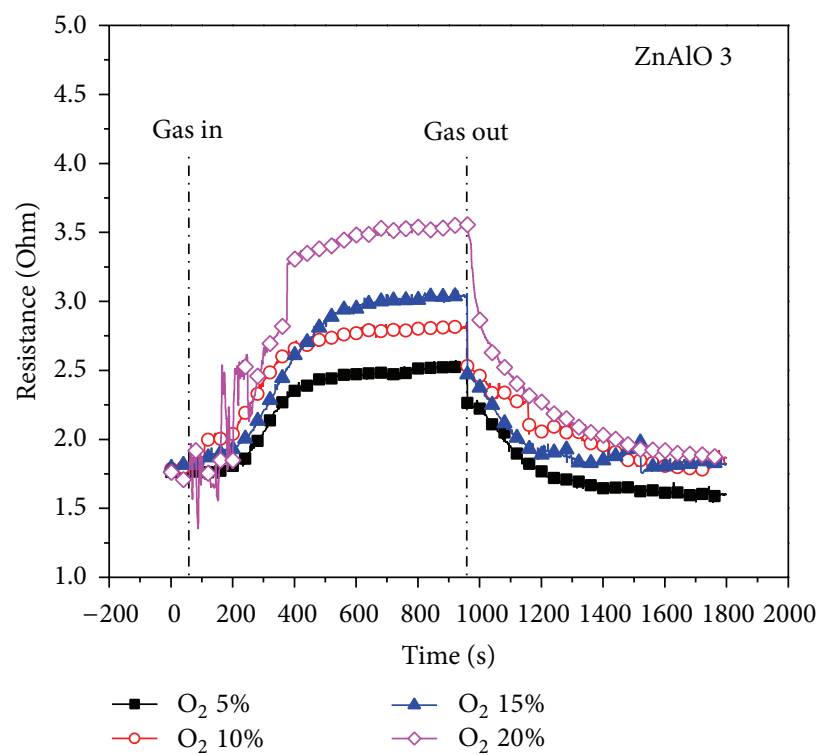

(d)

FIGURE 3: The effect of aluminum content on the resistance of zinc aluminum oxide gas sensor upon exposure to the various concentrations of oxygen at an operating temperature of $100^{\circ} \mathrm{C}$.

TABLE 1: Al content, surface tension, and critical force to form nanowire of zinc-aluminum alloys prepared in this study.

\begin{tabular}{lcccc}
\hline Material & Aluminum content (wt.\%) & Surface tension at $750^{\circ} \mathrm{C}($ dyne $/ \mathrm{cm})$ & Critical force to form nanowire (dyne) & Alloy oxide \\
\hline Zn-Al alloy1 & $2 \%$ & 726.17 & $3.01 \times 10^{8}$ & ZnAlO 1 \\
Zn-Al alloy2 & $5 \%$ & 735.23 & $2.96 \times 10^{8}$ & ZnAlO 2 \\
Zn-Al alloy3 & $10 \%$ & 748.82 & $2.92 \times 10^{8}$ & ZnAlO 3 \\
\hline
\end{tabular}

$P=F / A=-(2 \gamma \cos \theta) / r$, where $F$ is the normal force, $A$ is the area of the nanomold, $r$ is the radius of the nanochannel, $\gamma$ is the surface tension of the molten zinc aluminum alloy, and $\theta$ is the contact angle between the melt and the porous alumina membrane. Therefore, the forces required to inject the 3 molten zinc aluminum alloys into nanomolds are listed in Table 1 . Solidification proceeded using a water cooling method at the bottom of the chamber. Zinc aluminum nanowire array was formed after cooling to room temperature. Finally, zinc aluminum oxide nanowire 


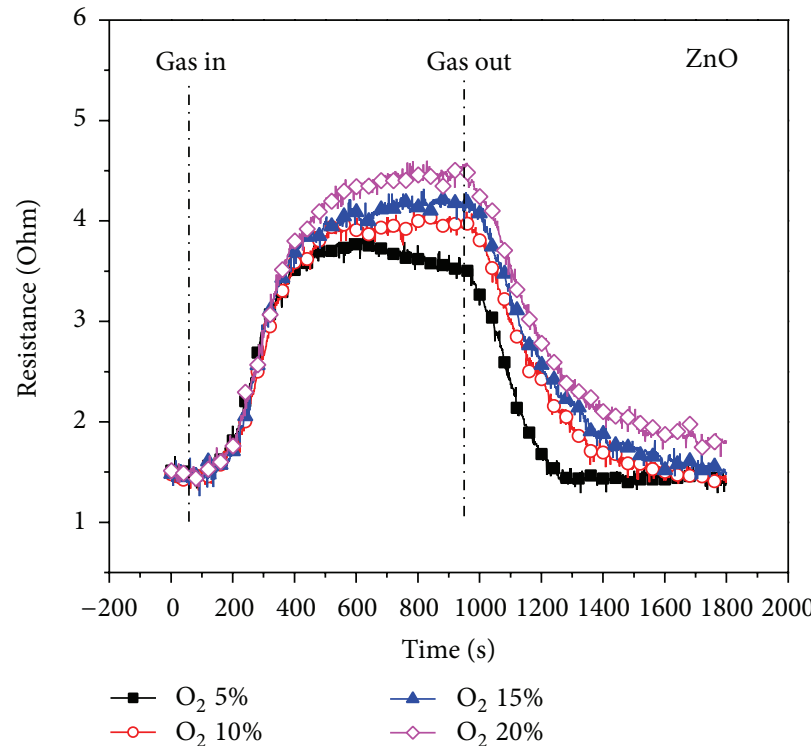

(a)

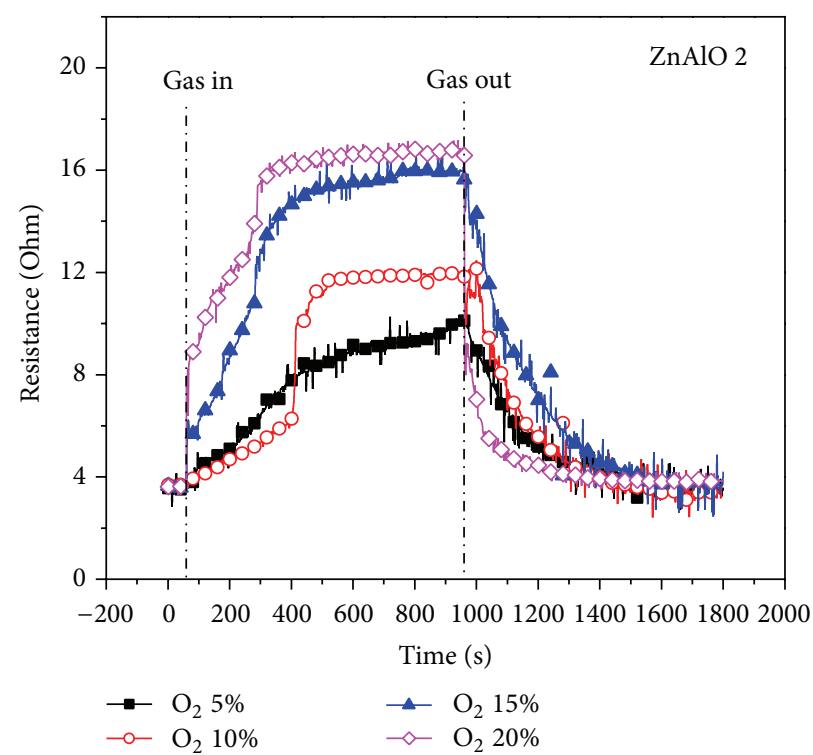

(c)

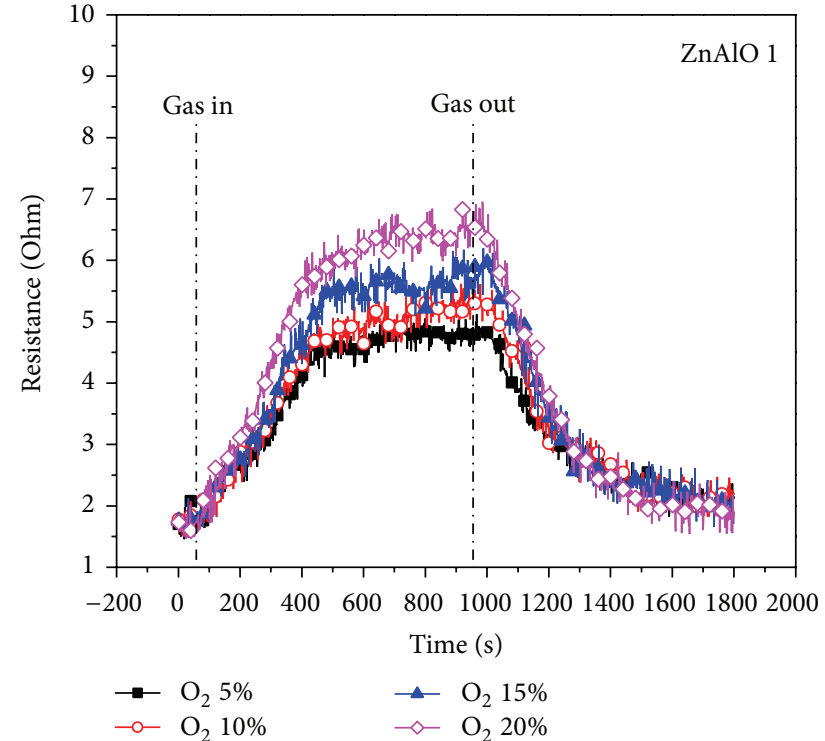

(b)

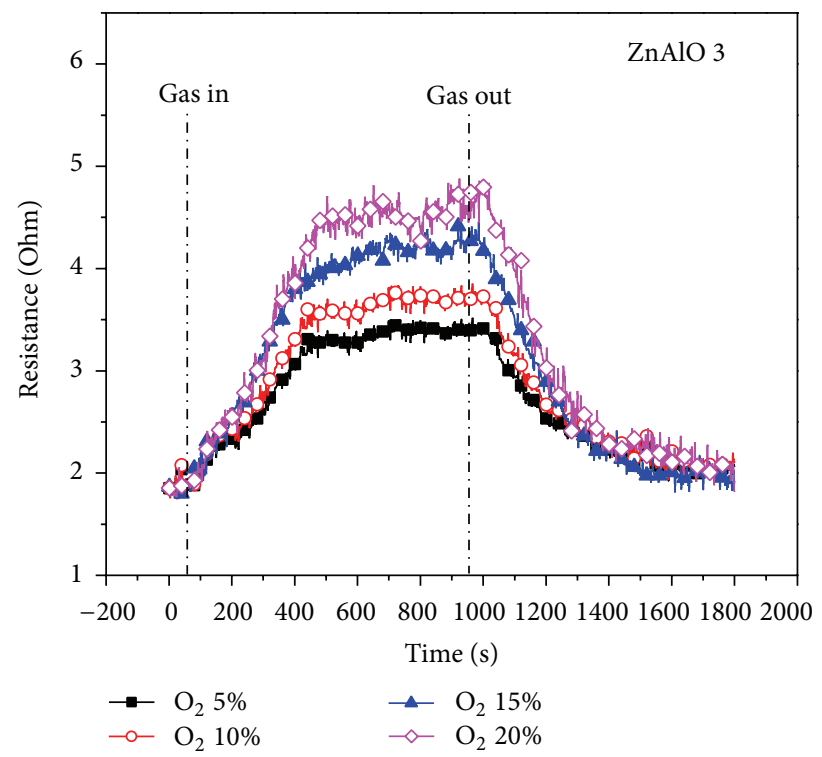

(d)

FIGURE 4: The effect of aluminum content on the resistance of zinc aluminum oxide gas sensor upon exposure to the various concentrations of oxygen at an operating temperature of $150^{\circ} \mathrm{C}$.

TABLE 2: Element compositions of 3 zinc aluminum alloys prepared by the vacuum melting method.

\begin{tabular}{lcc}
\hline Materials & Zn wt.\% & Al wt.\% \\
\hline Zn-Al alloyl & $97.96 \%$ & $2.04 \%$ \\
Zn-Al alloy2 & $94.96 \%$ & $5.04 \%$ \\
Zn-Al alloy3 & $89.71 \%$ & $10.29 \%$ \\
\hline
\end{tabular}

array was fabricated through a thermal oxidation process. The nanowire array was put into an air furnace and a heat treatment at $250^{\circ} \mathrm{C}$ for 48 hours was applied to make all the metal become metal oxide by reacting with oxygen and then zinc aluminum oxide nanowire array could be obtained.

$\mathrm{Cu}$ thin film was deposited at the top and bottom surface of zinc aluminum oxide nanowires array as the conductive layer of the gas sensor by vapor deposition technique. After that, aluminum oxide surrounding the nanowires was removed using sodium hydroxide solution. Figure 1 was the schematic diagram of zinc aluminum oxide nanowire array gas sensor produced in the present study.

The morphologies of the anodic alumina nanomold and zinc aluminum nanowire array were observed by scanning electron microscope. The gas sensing characteristics of zinc 


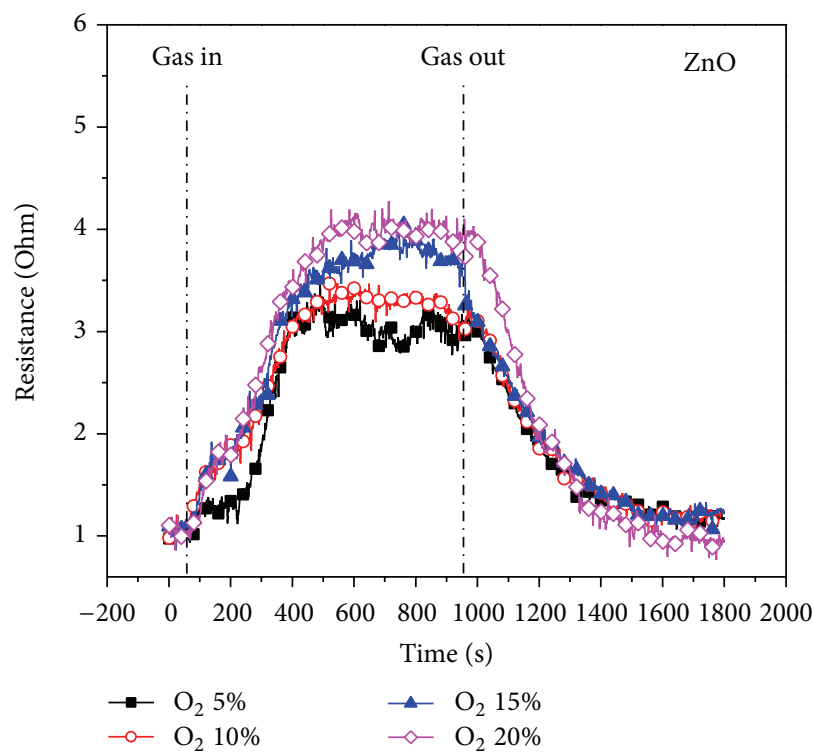

(a)

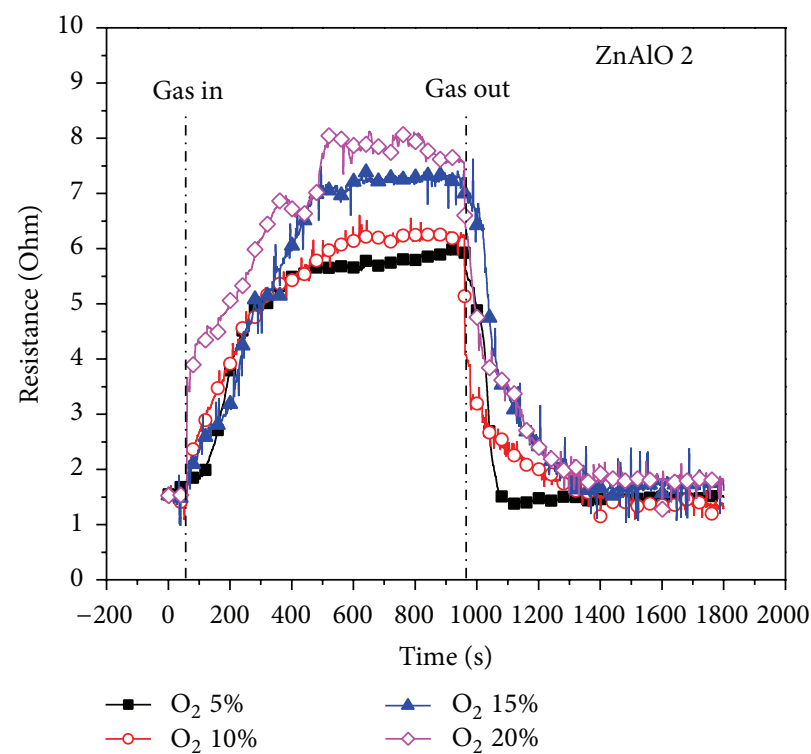

(c)

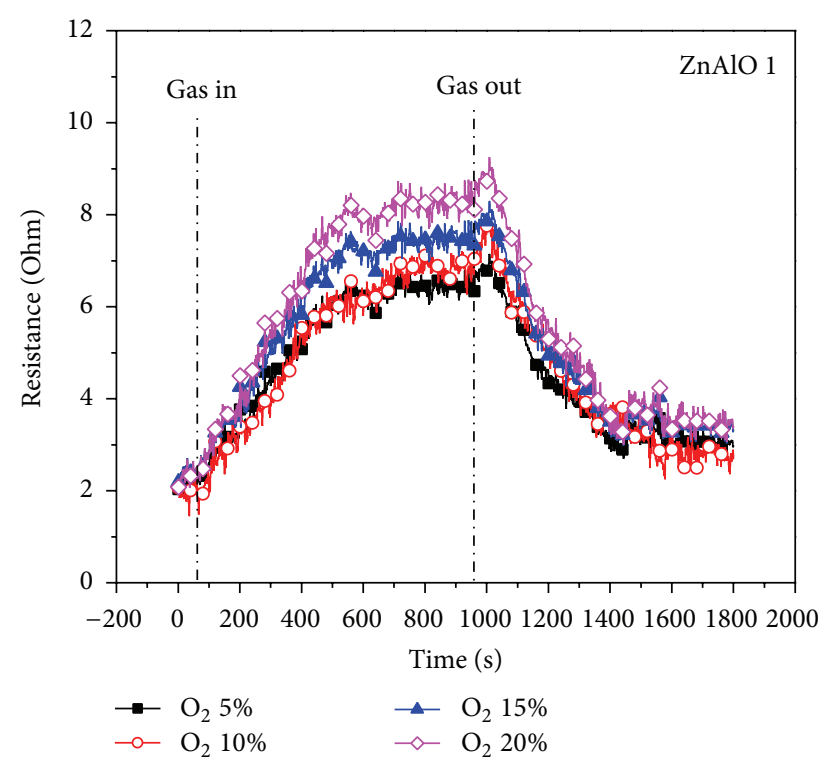

(b)

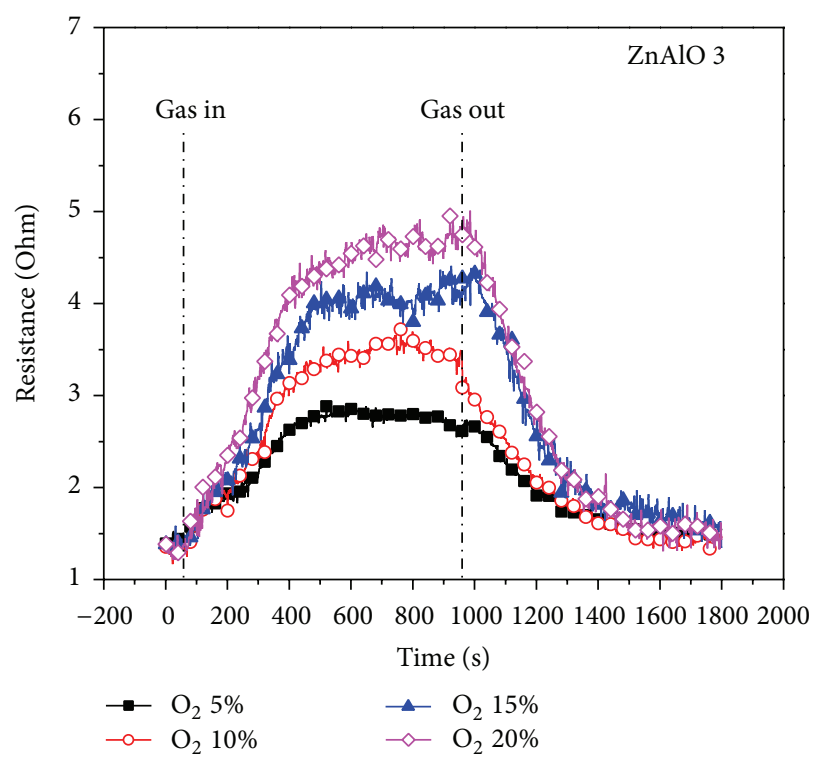

(d)

FIGURE 5: The effect of aluminum content on the resistance of zinc aluminum oxide gas sensor upon exposure to the various concentrations of oxygen at an operating temperature of $200^{\circ} \mathrm{C}$.

aluminum oxide gas sensor were measured by the selfdesigned gas sensor test system.

\section{Results and Discussion}

An anodic alumina nanomold was produced by etching a pure aluminum sheet with a purity of $99.7 \mathrm{wt} . \%$ in $0.3 \mathrm{M}$ oxalic acid solution for 6 hours. Figure 2(a) provided SEM image of the anodic aluminum nanomold with the pore diameter of $80 \mathrm{~nm}$ and an ordered and uniform array. The morphology of zinc aluminum nanowire array could be observed in Figure 2(b). The composition of zinc aluminum alloy prepared by the vacuum melting method was detected by EDX analysis and presented in Table 2 . The results were consistent with the design of the three zinc aluminum alloys.

Zinc oxide is a typical n-type semiconductor gas sensing material with direct band gap of about $3.37 \mathrm{eV}$ at room temperature [19]. An n-type semiconductor material means that the majority of charge carriers are electrons, and an increase in conductivity occurs when the material interacts with a reducing gas. Conversely, reacting with an oxidizing gas would cause a decrease in conductivity. In this study, four nanowire array gas sensors $(\mathrm{ZnO}, \mathrm{ZnAlO} 1, \mathrm{ZnAlO} 2$, 


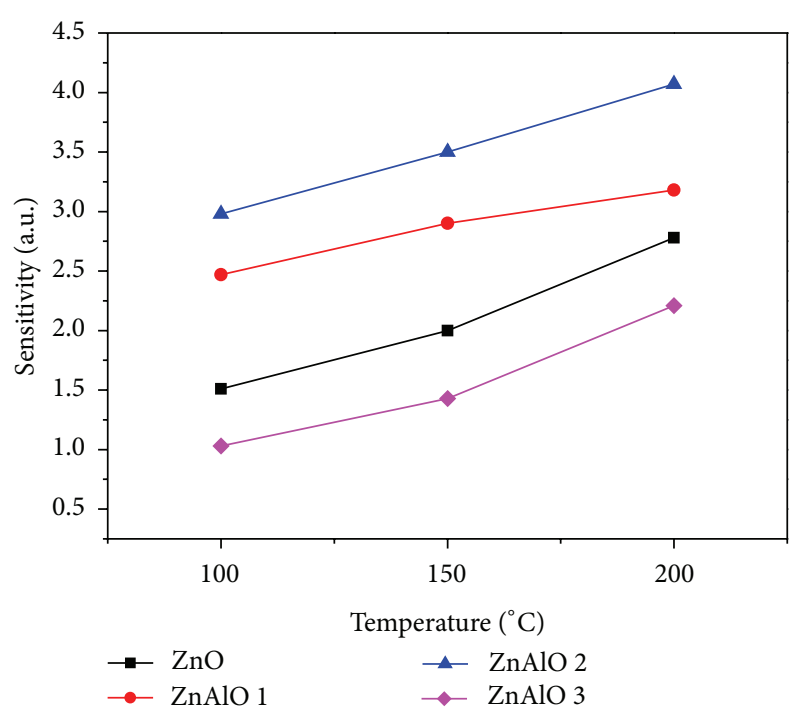

FIGURE 6: The operating temperature influence on the sensitivity of zinc aluminum oxide gas sensor upon exposure to oxygen $20 \mathrm{vol} . \%$.

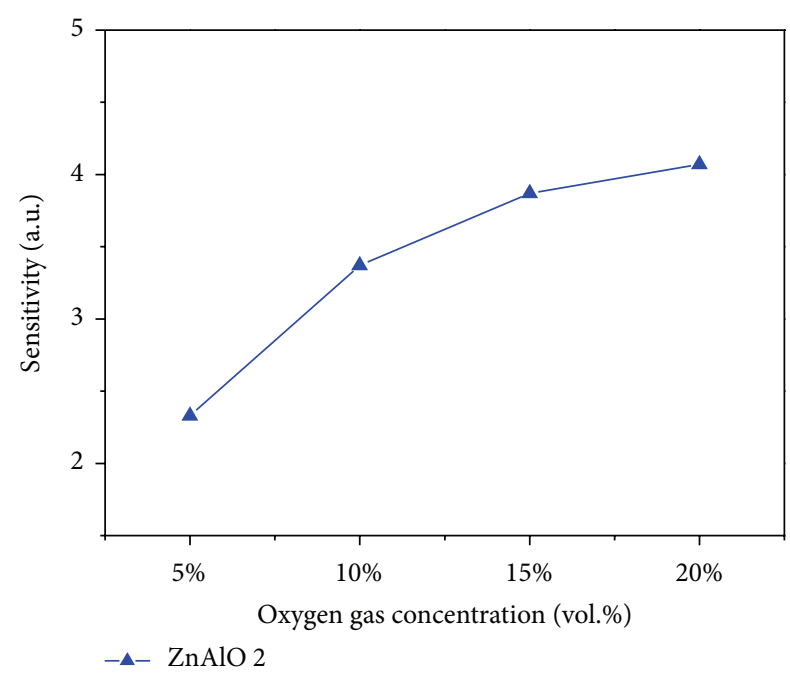

FIGURE 7: Oxygen concentration influence on the sensitivity of zinc aluminum oxide ( $\mathrm{ZnAlO} 2)$ gas sensor at an operating temperature of $200^{\circ} \mathrm{C}$

and $\mathrm{ZnAlO} 3$ ) were tested for the gas sensing properties and similar results were obtained as shown in Figures 3, 4, and 5. Figures 3-5 showed the time dependence of resistance of zinc aluminum oxide gas sensor on exposure to different concentrations of oxygen, $5 \%, 10 \%, 15 \%$, and $20 \%$. When oxygen was introduced into the measurement system, the resistance of zinc aluminum oxide gas sensor increased obviously. Based on the measurement results, zinc aluminum oxide nanowire array fabricated in this work had the same behavior as an n-type semiconductor. Besides, ZnAlO 2 had the better sensing properties, such as the change of the resistance after introduction of oxygen, the response time, and the recovery time, than other zinc aluminum oxide materials (ZnAlO 1 and $\mathrm{ZnAlO} 3$ ) and zinc oxide.
Sensitivity $(S)$, an important parameter of gas sensors, can be defined as the ratio of the absolute difference between the stabilized resistances of gas sensors in the target gas and in the reference gas to the resistance in the reference gas, usually the dry air: $S=\left|R_{\text {air }}-R_{\text {gas }}\right| / R_{\text {air }}[20] . R_{\text {gas }}$ stands for the resistance of the gas sensor in the target gas and $R_{\text {air }}$ means the resistance of the gas sensor in air. Sensitivities of four gas sensors on exposure to the same concentration of oxygen $(20 \%)$ at various operating temperatures were shown in Figure 6 . The results indicated that the sensitivity was highly correlated with the operating temperature and all gas sensors had the same tendency. The response of gas sensors to oxygen gas would be better at the higher operating temperature. It could also be seen that sensitivity of $\mathrm{ZnAlO}$ 2 gas sensor was significantly higher than those of the other three gas sensors. Furthermore, the effect of exposure to different concentrations of oxygen for $\mathrm{ZnAlO} 2$ gas sensor was shown in Figure 7. The sensitivity of the gas sensor to oxygen increased with the concentration of oxygen.

\section{Conclusions}

A miniature n-type semiconductor gas sensor provided in this study was performed with the zinc aluminum oxide nanowire array. Using the vacuum die casting and thermal oxidation technique, zinc aluminum oxide nanowire whose diameter was $80 \mathrm{~nm}$ could be fabricated; moreover, the order, uniform, and large area of nanowire array was very suitable for the device manufacture. The gas sensing properties responding to oxygen of the zinc aluminum oxide gas sensor were investigated. According to the results of the gas sensing characteristics measurement, zinc aluminum oxide nanowire array prepared from the zinc aluminum alloy consisting of 94.96 wt.\% zinc and 5.04 wt.\% aluminum had the optimum sensing properties. The sensitivity of the zinc aluminum oxide gas sensor increased with the operating temperature or the introduced oxygen concentration

\section{Conflict of Interests}

The authors declare that there is no declare of interests regarding the publication of this paper.

\section{Acknowledgments}

The authors acknowledge the financial support of NSC 1023113-S-003-008-G and NSC 102-3113-S-262-001.

\section{References}

[1] G. Eranna, B. C. Joshi, D. P. Runthala, and R. P. Gupta, "Oxide materials for development of integrated gas sensorsa comprehensive review," Critical Reviews in Solid State and Materials Sciences, vol. 29, no. 3-4, pp. 111-188, 2004.

[2] G. F. Fine, L. M. Cavanagh, A. Afonja, and R. Binions, "Metal oxide semi-conductor gas sensors in environmental monitoring," Sensors, vol. 10, no. 6, pp. 5469-5502, 2010.

[3] N. Yamazoe, K. Suematsu, and K. Shimanoe, "Gas reception and signal transduction of neat tin oxide semiconductor sensor for 
response to oxygen," Thin Solid Films, vol. 548, pp. 695-702, 2013.

[4] R. K. Meruva and M. E. Meyerhoff, "Catheter-Type sensor for potentiometric monitoring of oxygen, $\mathrm{pH}$ and carbon dioxide," Biosensors and Bioelectronics, vol. 13, no. 2, pp. 201-212, 1998.

[5] K. Sadek and W. Moussa, "Studying the effect of deposition conditions on the performance and reliability of MEMS gas sensors," Sensors, vol. 7, no. 3, pp. 319-340, 2007.

[6] S. Sharma and M. Madou, "Review article: a new approach to gas sensing with nanotechnology," Philosophical Transactions of the Royal Society A, vol. 370, no. 1967, pp. 2448-2473, 2012.

[7] C. Wang, L. Yin, L. Zhang, D. Xiang, and R. Gao, "Metal oxide gas sensors: sensitivity and influencing factors," Sensors, vol. 10, no. 3, pp. 2088-2106, 2010.

[8] G. Korotcenkova and B. K. Cho, "Instability of metal oxidebased conductometric gas sensors and approaches to stability improvement (short survey)," Sensors and Actuators B, vol. 156, no. 2, pp. 527-538, 2011.

[9] A. Wisitsoraat, A. Tuantranont, E. Comini, G. Sberveglieri, and W. Wlodarski, "Characterization of n-type and p-type semiconductor gas sensors based on $\mathrm{NiO}_{x}$ doped $\mathrm{TiO}_{2}$ thin films," Thin Solid Films, vol. 517, no. 8, pp. 2775-2780, 2009.

[10] X. Huang, F. Meng, Y. Sun, and J. Liu, "Study of factors influencing dynamic measurements using $\mathrm{SnO}_{2}$ gas sensor," Sensors and Materials, vol. 17, no. 1, pp. 29-38, 2005.

[11] G. Korotcenkov, S.-D. Han, B. K. Cho, and V. Brinzari, "Grain size effects in sensor response of nanostructured $\mathrm{SnO}_{2}$ - and $\mathrm{In}_{2} \mathrm{O}_{3}$-based conductometric thin film gas sensor," Critical Reviews in Solid State and Materials Sciences, vol. 34, no. 1-2, pp. 1-17, 2009.

[12] S. Aygün and D. Cann, "Hydrogen sensitivity of doped $\mathrm{CuO} / \mathrm{ZnO}$ heterocontact sensors," Sensors and Actuators B, vol. 106, no. 2, pp. 837-842, 2005.

[13] A. Rothschild and Y. Komem, "The effect of grain size on the sensitivity of nanocrystalline metal-oxide gas sensors," Journal of Applied Physics, vol. 95, no. 11 I, pp. 6374-6380, 2004.

[14] G. N. Chaudhari, D. R. Bambole, A. B. Bodade, and P. R. Padole, "Characterization of nanosized $\mathrm{TiO}_{2}$ based $\mathrm{H}_{2} \mathrm{~S}$ gas sensor," Journal of Materials Science, vol. 41, no. 15, pp. 4860-4864, 2006.

[15] C.-G. Kuo, H. Chang, L.-R. Hwang et al., "Fabrication of a PbSn nanowire array gas sensor using a novel high vacuum die casting technique," Electronic Materials Letters, vol. 9, no. 4, pp. 481-484, 2013.

[16] J.-H. Chen, S.-C. Lo, C.-G. Chao, and T.-F. Liu, "Microstructure and properties of $\mathrm{Pb}$ nanowires fabricated by casting," Japanese Journal of Applied Physics, vol. 47, no. 6, pp. 4815-4819, 2008.

[17] I. S. Grigoriev and E. Z. Meilikhov, Handbook of Physical Quantities, CRC Press, Boca Raton, Fla, USA, 1997.

[18] Z. Zhang, J. Y. Ying, and M. S. Dresselhaus, "Bismuth quantumwire arrays fabricated by a vacuum melting and pressure injection process," Journal of Materials Research, vol. 13, no. 7, pp. 1745-1748, 1998.

[19] S. K. Arya, S. Saha, J. E. Ramirez-Vick, V. Gupta, S. Bhansali, and S. P. Singh, "Recent advances in $\mathrm{ZnO}$ nanostructures and thin films for biosensor applications: review," Analytica Chimica Acta, vol. 737, pp. 1-21, 2012.

[20] S. K. Gupta, A. Joshi, and K. Manmeet, "Development of gas sensors using $\mathrm{ZnO}$ nanostructures," Journal of Chemical Sciences, vol. 122, no. 1, pp. 57-62, 2010. 

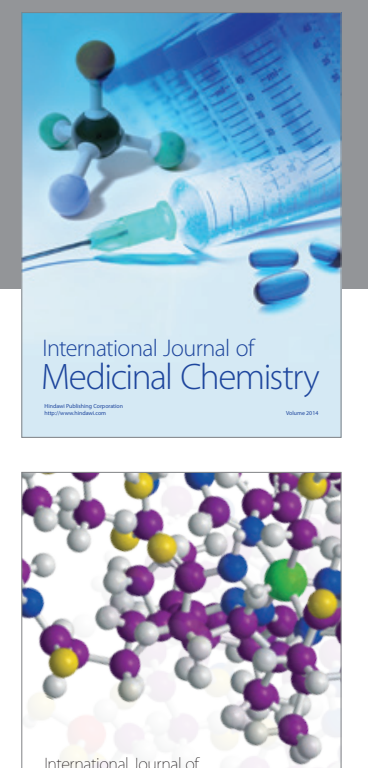

\section{Carbohydrate} Chemistry

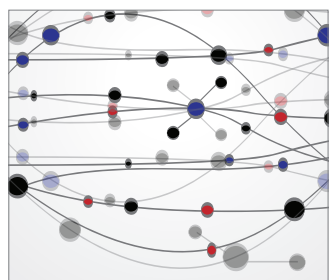

The Scientific World Journal
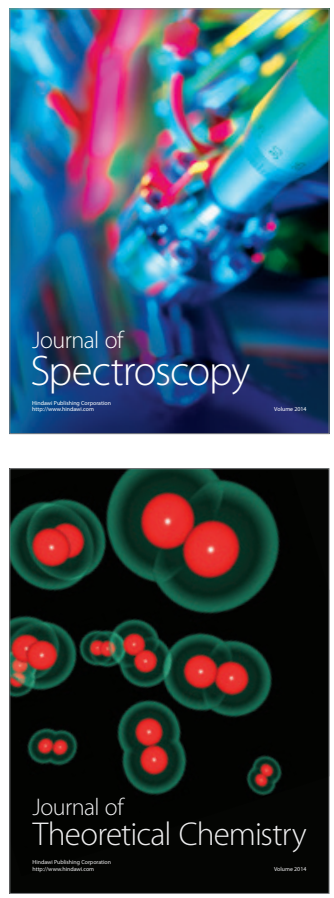
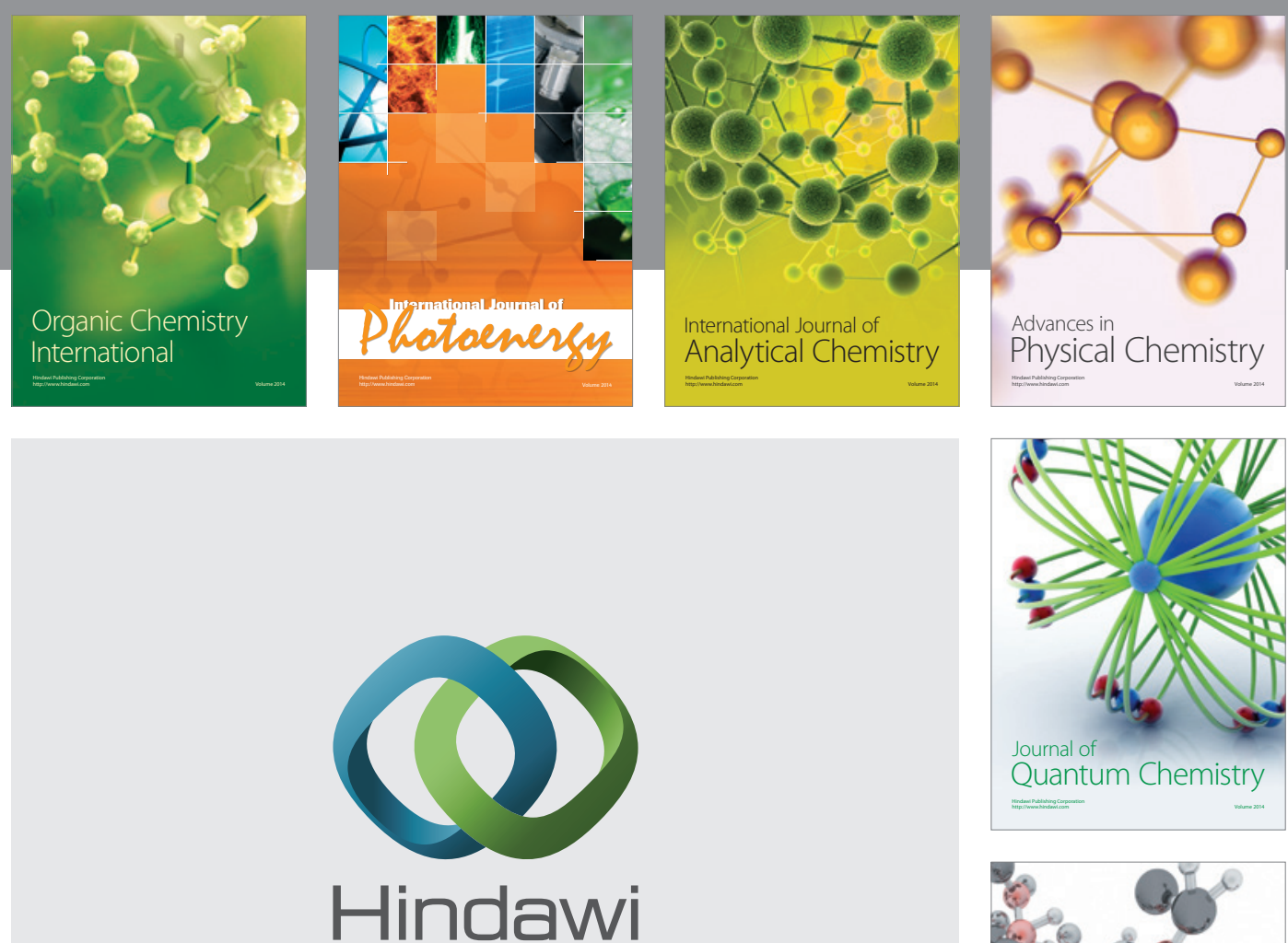

Submit your manuscripts at

http://www.hindawi.com

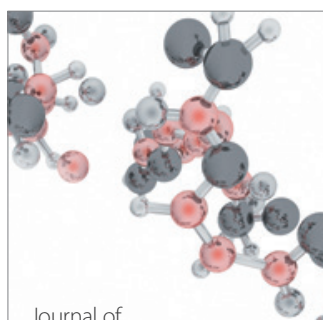

Analytical Methods

in Chemistry

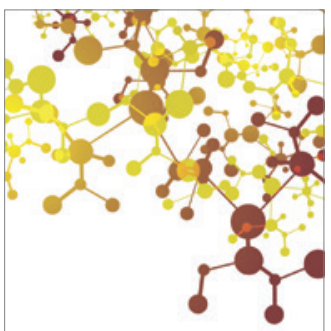

Journal of

Applied Chemistry

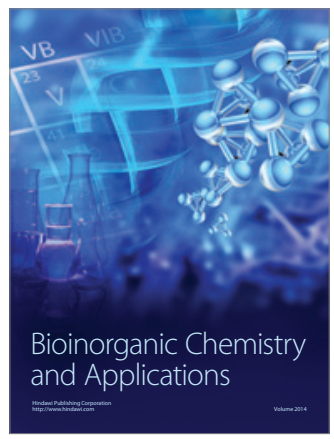

Inorganic Chemistry
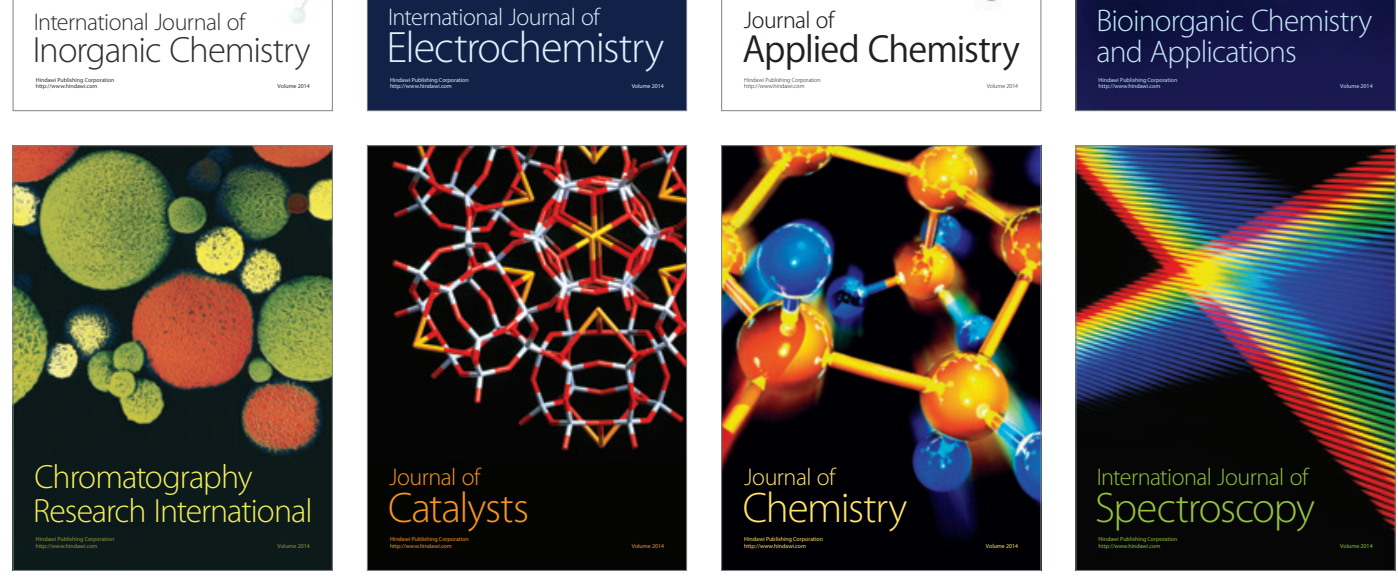